PAPER

\title{
Correlation between clinical characteristics and proliferative activity in patients with craniopharyngioma
}

\author{
M Losa, A Vimercati, S Acerno, R L Barzaghi, P Mortini, F Mangili, M R Terreni, G Santambrogio, \\ M Giovanelli
}

J Neurol Neurosurg Psychiatry 2004;75:889-892. doi: 10.1136/jnnp.2003.012781

See end of article for authors' affiliations

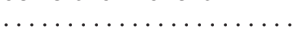

Correspondence to: Dr M Losa, Department of Neurosurgery, Istituto Scientifico San Raffaele, Via Olgettina 60 20132-Milan, Italy; losa.marco@hsr.it

Received 14 February 2003 Revised 7 October 2003 Accepted 17 October 2003
Objectives: The aim of the study was to correlate the Ki-67 and cyclin A labelling index (LI) with clinical characteristics and risk of recurrence of craniopharyngiomas.

Methods: 47 consecutive patients were studied, 21 female and 26 male, aged 34.3 (2.8) years. Immunohistochemical analysis was performed on paraffin wax embedded material using monoclonal antibodies directed against the proliferation associated nuclear antigen $\mathrm{Ki}-67$ and cyclin $\mathrm{A}$.

Results: The median Ki-67 LI was $8.6 \%$ (interquartile range, $4.4 \%-14.0 \%$ ). Ki-67 LI was significantly higher in tumours with a heavy inflammatory reaction and diabetes insipidus at presentation, whereas other clinical and histological features were not associated with the proliferation index. There was a strong linear correlation between $\mathrm{Ki}-67 \mathrm{LI}$ and cyclin A LI $(r=0.77 ; \mathrm{p}<0.0001)$; therefore, cyclin A LI showed the same clinical and histological relations described for Ki-67 LI. Recurrence of craniopharyngioma occurred in 13 of 46 patients (28.3\%). The median $\mathrm{Ki}-67 \mathrm{LI}$ in the 13 recurrent craniopharyngiomas $(9.0 \%)$ was not significantly different from that of non-recurring tumours (7.9\%). Cyclin A LI was also not associated with the risk of relapse.

Conclusions: This study confirms the great variability of proliferative activity in craniopharyngiomas. Ki-67 and cyclin A Lls were associated with the presence of a heavy inflammatory reaction and diabetes insipidus, but did not correlate with the long term risk of tumour regrowth.

\footnotetext{
C
} raniopharyngiomas are histologically benign tumours of the sellar region that account for $1.2 \%$ to $4.6 \%$ of all intracranial tumours. Their annual incidence is 0.5 to 2.5 cases per million population. ${ }^{12}$ There is a bimodal age distribution of incidence rates with a first peak in patients aged 5 to 14 years and a second peak between the ages of 50 and 74 years. $^{2}{ }^{3}$ Surgical removal of the lesion is the first choice treatment, whereas radiation therapy is usually reserved to diminish the risk of recurrence in patients with incomplete tumour resection. Reliable objective morphological criteria for predicting tumour behaviour are, however, still lacking.

Ki-67 is a nuclear antigen expressed in all phases of the cell cycle except G0. ${ }^{4}$ Expression of Ki-67 is a requirement for cells to traverse the cell cycle and undergo cell division ${ }^{5}$ and, therefore, all types of proliferating human cells express Ki67. ${ }^{7}$ The cyclins are proteins that play an important part in the control of cell proliferation, being essential for passage through specific stages of the cell cycle. ${ }^{8}$ In particular, cells expressing cyclin A are committed to cell division. ${ }^{9}$ Therefore, determination of the cells expressing cyclin A might represent a more specific measure of the growth fraction of a specified tissue.

The aim of our study was to measure the Ki-67 labelling index (LI) and cyclin A LI in a consecutive series of patients with craniopharyngioma.

\section{METHODS}

\section{Patients}

Tumour specimens were obtained from 47 consecutive patients with craniopharyngioma, operated on between January 1990 and December 2000 at our hospital. The study included 21 female patients $(45 \%)$ and 26 male patients (55\%) with a mean (SE) age of 34.3 (2.8) years, ranging from 6 to 78 years. Sixteen patients $(34.0 \%)$ were $\leqslant 18$ years of age at the time of surgery. Ten patients had previously been operated (two by us and eight in other hospitals). The reason for surgery was recurrence of the tumour in three cases and unsuccessful removal in the remaining seven patients. Only one patient had received radiation therapy before surgery.

Presenting symptoms, hormonal, and neuroradiological data were prospectively recorded for each patient. Follow up included first postoperative magnetic resonance imaging (MRI) two to six months after surgery and then at variable intervals, depending on the clinical and neuroradiological situation. Recurrence of craniopharyngioma during follow up was defined as evidence at repeat MRI of pathological tissue not detected earlier or growth of residual neoplastic tissue in comparison with the previous MRI.

\section{Histological analysis}

Surgically removed specimens were fixed immediately in 10\% buffered formalin and subsequently embedded in paraffin wax. Standard haematoxylin and eosin sections were used for diagnosis. Craniopharyngiomas were subdivided into adamantinomatous and papillary tumours. Tumours with mixed characteristics were classified as adamantinomatous type.

\section{MIB-1 and cyclin A immunostaining}

Ki-67 antigen was detected by means of the monoclonal antibody MIB-1, which can be used in formalin fixed paraffin wax embedded specimens. MIB-1 and cyclin A immunostaining were performed using the avidin-biotin-peroxidase complex method on $4 \mu \mathrm{m}$ thick sections serially obtained from the paraffin wax embedded tissue. Antigen retrieval was obtained by microwave treatment (two passages at 850 Watts of five minutes each). MIB-1 monoclonal antibody

Abbreviations: LI, labelling index; MRI, magnetic resonance imaging 
diluted 1:50 (Immunotech SA, Marseille, France) or anticyclin A monoclonal antibody diluted 1:100 (Amersham) were used as primary antibodies. No MIB-1 or cyclin A antisera were added on sections used as negative controls. The Ki-67 and cyclin A LIs were determined by a single pathologist (FM), who was unaware of the clinical characteristics of the patients. A total of at least 1000 neoplastic nuclei, subdivided in 10 fields chosen randomly at $\times 400$ magnification, were counted.

\section{Statistical analysis}

Ki-67 LI and cyclin A LI were transformed logarithmically before statistical analysis, because they were not normally distributed. However, in the text and figures Ki-67 LI and cyclin A LI are given in the more usual decimal format. Continuous data are expressed as mean (SE), except for Ki$67 \mathrm{LI}$ and cyclin A LI, which are presented as median values with interquartile ranges. Student's $t$ test for unpaired data was used to compare continuous variables among groups. Correlation coefficient between Ki-67 LI and cyclin A LI was calculated by the method of least squares. Stepwise regression analysis was used to test the association between Ki-67 LI and clinical and histological characteristics of the patients. The Kaplan-Meier method was used to analyse the primary end point of recurrence of craniopharyngioma during follow up. Recurrence free survival was measured from the date of surgery to the date of relapse and was censored at the date of the last MRI follow up.

A p value of less than 0.05 was considered to indicate significance.

\section{RESULTS}

\section{$\mathrm{Ki}-67$ and cyclin A Lls}

Table l summarises the clinical characteristics of the study population. The median Ki-67 LI in all patients was $8.6 \%$ $(4.4 \%-14 \%)$. Table 2 shows the univariate analysis of the associations between Ki-67 LI and several clinical characteristics of the patients. Because of the possible relations among some of the variables, we then construed a multivariate analysis, including in the model those variables that had a $\mathrm{p}<0.10$ in the univariate analysis plus age and maximum tumour diameter. Stepwise regression analysis showed that only heavy flogistic reaction $(\mathrm{p}<0.01)$ and diabetes insipidus at presentation $(\mathrm{p}<0.01)$ were independently and positively associated with a high Ki-67 LI, whereas age, maximum tumour diameter, and histological subtype had no independent value.

Cyclin A LI could not be evaluated in three samples because of technical failure. The median cyclin A LI in the remaining 44 patients was $3.6 \%(1.5 \%-6.6 \%)$. There was a strong linear correlation between Ki-67 LI and cyclin A LI $(r=0.77 ; \mathrm{p}<0.0001$; fig 1$)$. Because of the strong correlation between the two variables, cyclin A LI showed the same relations described for Ki-67 LI with clinical and histological variables.

\section{$\mathrm{Ki}-67$ and cyclin A Lls and the risk of recurrence}

One patient died one week after operation because of hypothalamic derangement. Mean (SE) follow up for the remaining 46 patients was 60.4 (5.2) months, ranging from 3 to 141 months. The first postoperative MRI showed no residual tumour in 29 patients $(63.0 \%)$, whereas pathological tissue was present in the remaining 17 patients $(37.0 \%)$.

Recurrence of craniopharyngioma occurred in 13 of the 46 patients $(28.3 \%)$. The disease free interval at five years was $69.6 \%$ (95\% confidence intervals, $55.0 \%$ to $84.3 \%$ ). The median Ki-67 and cyclin A LIs in the 13 recurrent craniopharyngiomas $(9.0 \%$ and $2.9 \%$, respectively) were not significantly different from that of non-recurring tumours
Table 1 Clinical characteristics of patients operated for a craniopharyngioma

\begin{tabular}{ll}
\hline Characteristics & $\mathbf{n = 4 7}$ \\
\hline Female sex (\%) & $21(44.7)$ \\
Age (y) (SE) & $34.3(2.8)$ \\
Hypogonadism (\%) & $36(76.2)$ \\
Hypothyroidism (\%) & $23(48.9)$ \\
Hypoadrenalsim (\%) & $23(48.9)$ \\
Diabetes insipidus (\%) & $20(42.5)$ \\
Visual defects (\%) & $40(85.1)$ \\
Mass effect symptoms (\%) & $12(25.5)$ \\
Maximum tumour diameter (mm) (SE) & $32.1(1.7)$ \\
Cystic tumour (\%) & $43(91.5 \%)$ \\
Tumour calcifications (\%) & $26(55.3)$ \\
Suprasellar extension (\%) & $45(95.7)$ \\
Transcranial approach (\%) & $40(85.1)$ \\
Apparent complete removal (\%) & $33(70.2)$ \\
Adamantinomatous subtype (\%) & $44(93.6)$ \\
Infiltration of nervous tissue (\%) & $6(12.8)$ \\
Infiltration of pituitary (\%) & $5(10.6)$ \\
Flogistic infiltration of the tumour (\%) & $10(21.3)$
\end{tabular}

(7.9\% and 5.0\%, respectively). Both Ki-67 and cyclin LIs had no independent prognostic value on the risk or recurrence either when computed as continuous or categorical variables (fig 2).

\section{DISCUSSION}

Despite their benign histological nature, craniopharyngiomas may behave aggressively and recur even after apparent complete surgical removal. The median Ki-67 LI in our study population was $8.6 \%$, with a wide range of values, from $0.1 \%$ to $40 \%$. Other studies found a mean (SD) Ki-67 LI of 10.8 $(8.0) \%$ and $7.8(7.9) \%$ in 17 and 37 patients, respectively. ${ }^{10}{ }^{11}$ In another study involving only children, the mean (SD) Ki67 LI was $4.7(2.3) \% .^{12}$ To put these values into perspective, pituitary adenomas, the most frequent benign tumour of the pituitary gland, seem to have a lower proliferation activity. ${ }^{13-15}$

Among several characteristics, only presence of a strong inflammatory reaction and diabetes insipidus at presentation were independently associated with high Ki-67 LI. It is possible that craniopharyngiomas with a high proliferative index may induce a strong inflammatory reaction. It is more difficult to explain the apparent association between diabetes insipidus and Ki-67 LI. One possible explanation is that diabetes insipidus is a surrogate marker for an infiltrating and more aggressive tumour behaviour. However, we caution against overinterpretation of these results because of the small sample size of the study population.

Cyclin A LI was almost 50\% lower than Ki-67 LI and strongly correlated with it. This finding implies that in craniopharyngiomas most cells entering the mitotitc cycle proceed until the late stages of the cycle with few losses. Therefore, measurement of cyclin A does not add more information than that obtained by Ki-67 LI determination alone.

As for other benign tumours of the sellar region, the factors contributing to the long term prognosis are complex. Tumour recurrence is one of the most fearful complications in patients operated for a craniopharyngioma and has strong adverse consequences on survival and quality of life. Recurrence rates from 5\% to 57\% have been reported in large series of craniopharyngiomas. ${ }^{3}{ }^{12-26}$ The variability of the reported recurrence rates is probably attributable to various factors, such as different definitions of recurrence (clinical or neuroradiological), whether surgery was aimed at total or partial removal of the tumour and whether radiation therapy 


\begin{tabular}{|c|c|c|c|}
\hline Variables & & $\begin{array}{l}\text { Median Ki-67 LI } \\
(25-75 \text { interquartile range) } \\
(\%)\end{array}$ & p Value \\
\hline \multirow[t]{2}{*}{ Sex } & Male $(n=26)$ & $7.1(3.6-14.0)$ & \\
\hline & Female $(n=21)$ & $9.0(6.6-14.3)$ & 0.84 \\
\hline \multirow[t]{2}{*}{ Adult } & Yes $(n=31)$ & $8.6(4.1-13.5)$ & \\
\hline & No $(n=16)$ & $8.4(5.3-14.9)$ & 0.87 \\
\hline \multirow[t]{2}{*}{ Previous surgery } & Yes $(n=10)$ & $9.7(4.4-14.0)$ & \\
\hline & No $(n=37)$ & $8.5(4.4-12.5)$ & 0.62 \\
\hline \multirow{2}{*}{ Diabetes insipidus } & Yes $(n=20)$ & $10.2(8.7-20.5)$ & \\
\hline & No $(n=27)$ & $6.3(3.5-9.1)$ & 0.03 \\
\hline \multirow[t]{2}{*}{ Cystic tumour } & Yes $(n=43)$ & $8.9(4.9-14.0)$ & \\
\hline & No $(n=4)$ & $5.4(3.1-9.6)$ & 0.72 \\
\hline \multirow[t]{2}{*}{ Retrosellar extension } & Yes $(n=12)$ & $9.5(6.1-14.9)$ & \\
\hline & No $(n=35)$ & $8.5(3.7-13.5)$ & 0.64 \\
\hline \multirow[t]{2}{*}{ Tumour calcification } & Yes $(n=26)$ & $8.8(4.6-10.0)$ & \\
\hline & No $(n=21)$ & $8.5(4.3-18.7)$ & 0.86 \\
\hline \multirow[t]{2}{*}{ Papillary subtype } & Yes $(n=3)$ & $25.0(15.2-36.2)$ & \\
\hline & No $(n=44)$ & $8.1(4.2-12.2)$ & 0.01 \\
\hline \multirow[t]{2}{*}{ Flogistic reaction } & Yes $(n=10)$ & $16.5(9.2-24.0)$ & \\
\hline & No $(n=37)$ & $7.0(3.6-10.1)$ & $<0.001$ \\
\hline
\end{tabular}

was advised or not postoperatively. The recurrence rate in our study was $28 \%$ and almost all recurrences occurred within three years from surgery. The tendency to early recurrence has already been noted in other series. ${ }^{12} 16$

Our study failed to show any association between the proliferation activity of the tumour, assessed either by means of Ki-67 LI or cyclin A LI, and the risk of relapse. Our results are in agreement with those of others, ${ }^{11}{ }^{12}$ but in contrast with those of Nishi and coworkers ${ }^{10}$ who, in their series of 17 patients, identified a Ki-67 LI greater than $7 \%$ as strongly predictive of tumour recurrence. However, in the second study $^{10}$ there was an unusually high rate of recurrence $(76.5 \%)$ compared with our data $(28.3 \%)$. It is noteworthy that the same failure of Ki-67 LI to predict tumour recurrence has occurred in a similarly designed study involving patients with non-functioning pituitary adenomas ${ }^{13}$ and in odontogenic tumours, which share several histological and behavioural characteristics with craniopharyngiomas. ${ }^{27}$

In conclusion, our study confirms the great variability of proliferative activity in craniopharyngiomas. Both Ki-67 LI and cyclin A LI were associated with the presence of

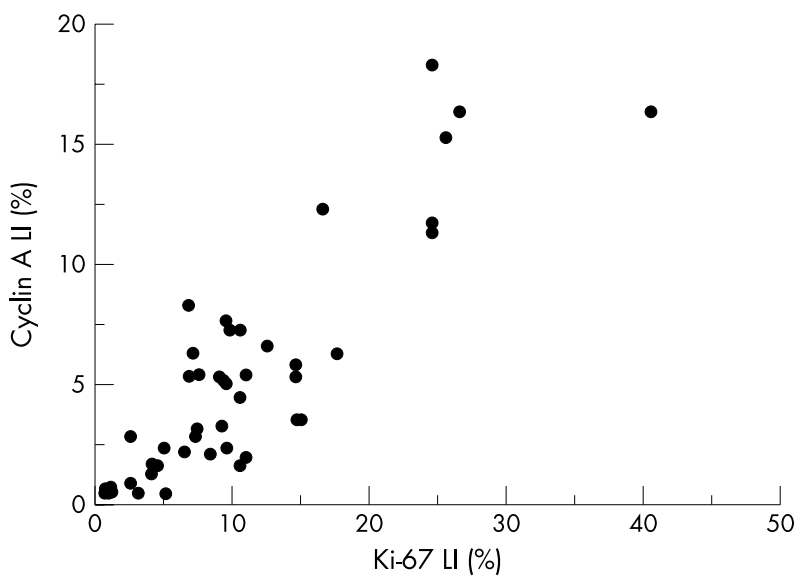

Figure 1 Correlation between $\mathrm{Ki}-67 \mathrm{LI}$ and cyclin A LI (shown as raw data) in 44 patients with craniopharyngioma. Regression analysis on log transformed data demonstrates a strong positive association between the two variables $(r=0.77 ; p<0.0001)$. The regression equation is $y=0.836 \times-0.201$. inflammatory reaction and diabetes insipidus, but did not correlate with the long term risk of tumour regrowth. Therefore, our data do not support the routine use of both variables to identify patients at higher risk of recurrence.
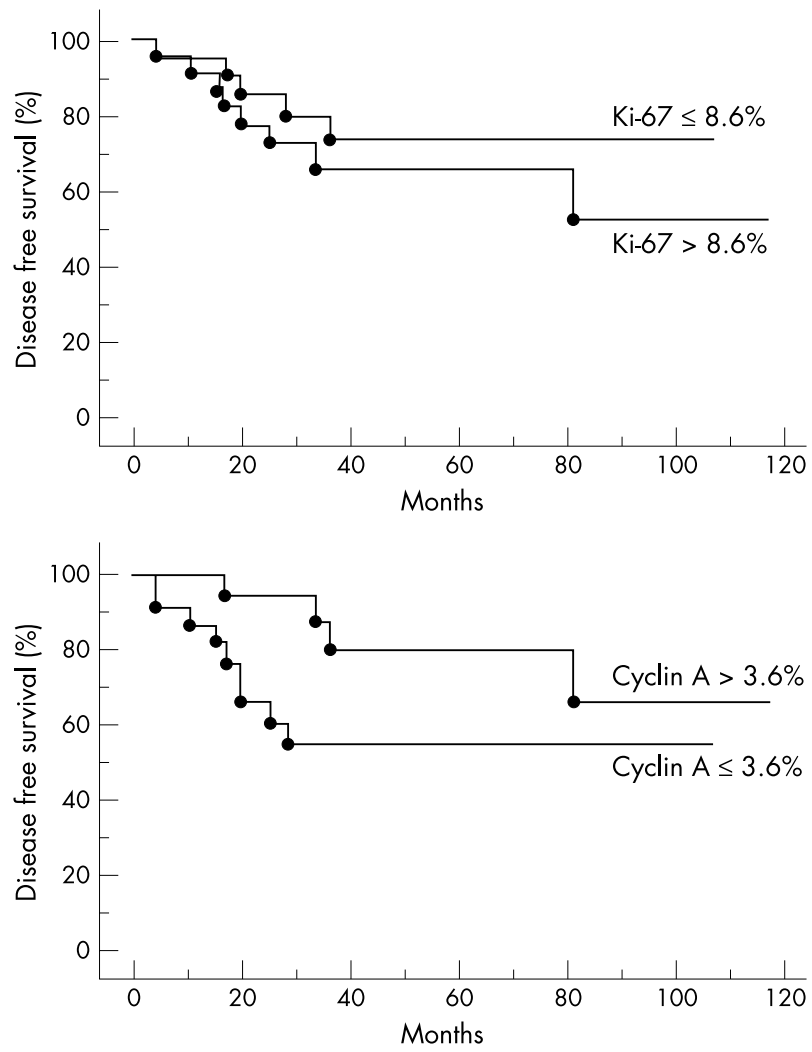

Figure 2 Kaplan-Meier analysis of the effect of Ki-67 (upper panel) and cyclin A (lower panel) Lls on the risk of recurrence of craniopharyngiomas. Both $\mathrm{Ki}-67$ and cyclin $\mathrm{A}$ have been categorised according to their median value $(8.6 \%$ and $3.6 \%$, respectively). There was no significant difference according to the log rank test $(p=0.37$ and $p=0.07$, respectively). Similar results were obtained when $\mathrm{Ki}-67$ and cyclin A Lls were categorised according to their $25 \%$ or $75 \%$ values. 


\section{ACKNOWLEDGEMENTS}

We thank Dr G Calori of the Clinical Epidemiology Unit of Istituto Scientifico San Raffaele for statistical advice.

\section{Authors' affiliations}

M Losa, A Vimercati, S Acerno, R L Barzaghi, P Mortini, M Giovanelli, Pituitary Unit, Department of Neurosurgery, Istituto Scientifico San Raffaele, University Vita-Salute, Milan, Italy

F Mangili, M R Terreni, G Santambrogio, Department of Pathology, Istituto Scientifico San Raffaele

Funding: none

Competing interests: none declared

\section{REFERENCES}

1 Zülch K. Brain tumors. Their biology and pathology. New York: SpringerVerlag, 1986

2 Bunin GR, Surawicz TS, Witman PA, et al. The descriptive epidemiology of craniopharyngioma. J Neurosurg 1998;89:547-51.

3 Szeifert GT, Sipos L, Horváth M, et al. Pathological characteristics of surgically removed craniopharyngiomas: analysis of 131 cases. Acta Neurochir (Wien) 1993; 124:139-43.

4 Losa M, Franzin A, Mortini P, et al. Usefulness of markers of cell proliferation in the management of pituitary adenomas. Clin Sci 1998:95:129-35.

5 Scholzen T, Gerdes J. The Ki-67 protein: from the known and the unknown. J Cell Physiol 2000;182:311-22.

6 MacCallum DE, Hall PA. The location of pKi67 in the outer dense fibrillary compartment of the nucleolus points to a role in ribosome biogenesis during the cell division cycle. J Pathol 2000;190:537-44.

7 Hall PA, Woods AL. Immunohistochemical markers of cellular proliferation: achievements, problems and prospects. Cell Tissue Kinet 1990;23:505-22.

8 Prosperi E, Stivala LA, Scovassi Al, et al. Cyclins: relevance of subcellular localization in cell cycle control. Eur J Histochem 1997;41:161-8.

9 Desdouets C, Sobezack-Thépot J, Murphy M, et al. Cyclin A: function and expression during cell proliferation. Prog Cell Cycle Res 1995;1:115-23.

10 Nishi T, Kuratsu Jl, Takeshima H, et al. Prognostic significance of the MIB-1 labeling index for patient with craniopharyngioma. Int J Mol Med 1999;3:157-61.
11 Ravaghan R, Dickey WT Jr, Margraf LR, et al. Proliferative activity in craniopharyngiomas: clinicopathological correlations in adults and children. Surg Neurol 2000;54:241-8.

12 Kim S-K, Wang K-C, Shin S-H, et al. Radical excision of pediatric craniopharyngioma: recurrence pattern and prognostic factors. Childs Nerv Syst 2001; 17:531-6.

13 Losa M, Franzin A, Mangili F, et al. Proliferation index of nonfunctioning pituitary adenomas: Correlations with clinical characteristics and long-term follow-up results. Neurosurgery 2000;47:1313-19.

14 Losa M, Barzaghi R, Mortini P, et al. Determination of the proliferation and apoptotic index in adrenocorticotropin-secreting pituitary tumors: comparison between micro- and macroadenomas. Am J Pathol 2000;156:245-51.

15 Losa M, Ciccarelli E, Mortini P, et al. Effects of octreotide treatment on the proliferation and apoptotic index of $\mathrm{GH}$-secreting pituitary adenomas. J Clin Endocrinol Metab 2001;86:5194-200.

16 Duff JM, Meyer FB, Ilstrup DM, et al. Long-term outcomes for surgically resected craniopharyngiomas. Neurosurgery 2000;46:291-305.

17 Adamson TE, Wiestler OD, Kleihues $\mathrm{P}$, et al. Correlation of clinical and pathological features in surgically treated craniopharyngiomas. J Neurosurg 1990;73:12-17.

18 Carmel PW, Antunes JL, Chang $\mathrm{CH}$. Craniopharyngiomas in children Neurosurgery 1982;11:382-9.

19 Stahnke N, Grubel G, Lagenstein I, et al. Long-term follow-up of children with craniopharyngioma. Eur J Pediatr 1984;142:179-85.

20 Fischer EG, Welch K, Shillito J Jr, et al. Craniopharyngiomas in children. Long-term effects of conservative surgical procedures combined with radiation therapy. J Neurosurg 1990;73:534-40.

21 Yasargil MG, Curcic M, Kis M, et al. Total removal of craniopharyngiomas. Approaches and long-term results in 144 patients. J Neurosurg 1990;73:3-11

22 Weiner $\mathrm{HL}$, Wisoff $\mathrm{H}$, Rosenberg ME, et al. Craniopahryngiomas: a clinicopathological analysis of factors predictive of recurrence and functional outcome. Neurosurgery 1994;35:1001-11.

23 Crotty TB, Scheithauer BW, Young WF, et al. Papillary craniopharyngioma: a clinicopathological study of 48 cases. J Neurosurg 1995;83:206-14.

24 Eldevik OP, Blaivas M, Gabrielsen TO, et al. Craniopharyngioma: radiologic and histologic findings and recurrence. Am J Neuroradio 1996:17:1427-39.

25 Villani RM, Tomei G, Bello L, et al. Long-term results of treatment for craniopharyngioma in children. Childs Nerv Syst 1997;13:397-405.

26 Fahlbusch R, Honegger J, Paulus W, et al. Surgical treatment of craniopharyngiomas: experience with 168 patients. J Neurosurg 1999.90:237-50.

27 Slootweg PJ. p53 protein and Ki-67 reactivity in epithelial odontogenic lesions. An immunohistochemical study. J Oral Pathol Med 1995;24:393-7. 